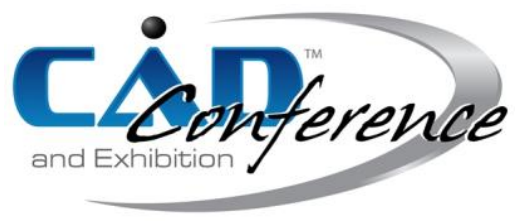

Title:

\title{
Application of the Generative Engineering Design in View of Solid or Surface Modelling
}

Authors:

Jana Gulanová, jana.gulanova@stuba.sk, Slovak University of Technology in Bratislava

Matúš Margetin, matus.margetin@stuba.sk, Slovak University of Technology in Bratislava

Andrej Chríbik, andrej.chribik@stuba.sk, Slovak University of Technology in Bratislava

Keywords:

Generative Engineering Design, solid modelling, surface modelling, CATIA, DfAM.

\section{DOI: 10.14733/cadconfP.2021.298-302}

\section{Introduction:}

Engineering design, sometimes referred to as industrial design, represents an important field within mechanical engineering. In automotive industry, it is an interconnecting point between styling design and further steps of the process, such as computational mechanics or kinematic simulations and preparation of a manufacturing technology. Manufacturing of complex subassemblies, such as those in vehicles, involves engineering design to support this process. A separate department of engineering designers dealing with manufacturing preparation develops fixtures, tools, or even entire assembly lines. For each purpose, a different modelling approach with its unique advantages is suitable.

The presented approaches are related to the Generative Design known in other fields of applied research. Firstly, it appeared in architecture and artistic fields. But later, its advantages were exploited also in other relevant areas [11].

Complex geometry introduces more constraints that have to be met to produce a valid result. The parametrization levels, and some practical solutions for its high-level use are well illustrated in [1,12]. Knowledge-Based Engineering (KBE) describes a wide range of CAD and CAE applications that are used in mutual cooperation, with an emphasis on knowledge reusability in repetitive tasks following normal engineering practices [14]. A part of such cooperation is related to the definition of specific parameters and other kinds of requirements in view of automatic design creation. Generative Engineering Design (GED) is generally a part of such a methodology [2,3,10]. The proposed methodology addresses two of current shortcomings of KBE, as identified in [15]. The unique advantage within the shape component design lies in the possibility to define models by the shape and position of surfaces. For instance, a surface of contact is difficult to set in solid modelling.

This paper deals with the comparison of two basic approaches to component design in automotive industry using advanced CAD system such as CATIA. Both approaches are presented with respect to modern designing methodologies known as Generative Design or Generative Engineering Design or Generative CAD.

$\underline{\text { Solid vs. Surface Modelling: }}$

Differences between the two main modelling approaches in CAD are summarized in the following and illustrated in Fig. 1.

Solid modelling

- A model is divided to volume objects referred to as bodies.

- Boolean operations replace basic operations to ensure robustness of the model.

- $\quad$ Component $=\mathrm{CAD}$ file . 
- Advanced engineering design is enabled by the creation of an intelligent parametric model or a skeleton model using formulas, scripts, relations, etc.

Surface Modelling

- Using wireframe and surface geometry commands the model is divided into folders referred to as Geometrical Sets.

- Auxiliary surfaces are created, trimmed and rounded.

- Continuity of a specific degree is ensured between the freeform surfaces.

- Advanced engineering design is enabled by means of auxiliary surfaces and CAD files referred to as parts.
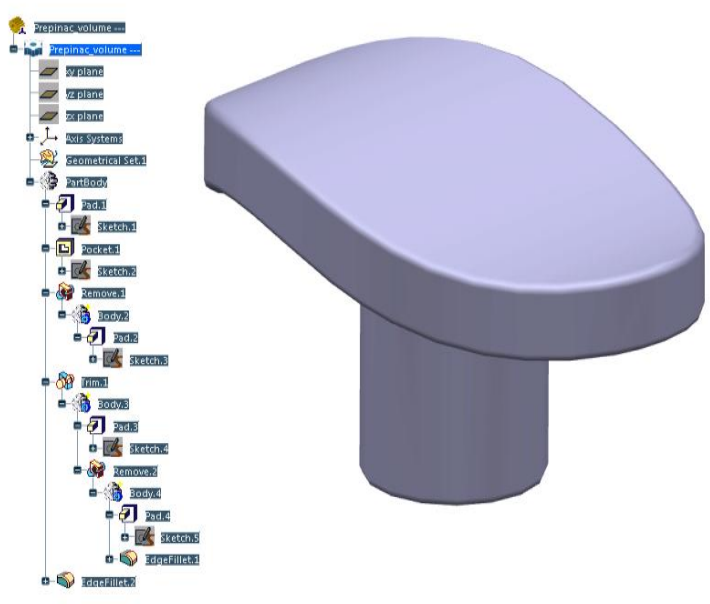

a)

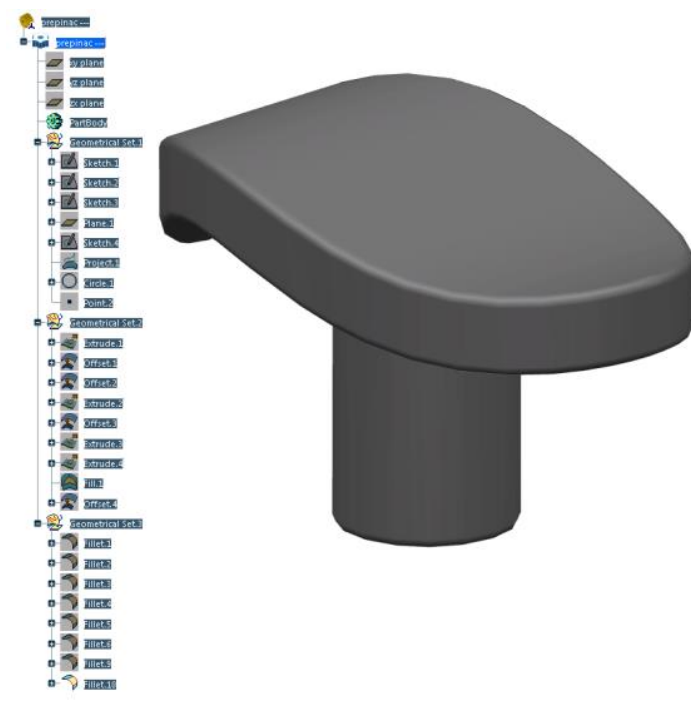

b)

Fig. 1: A model created by means of: a) solid modelling tools (tree with Boolean operations between bodies); b) surface modelling tools (tree with Geometrical Sets incorporating surface commands).

Generative Design in the View of Solid Modelling:

With respect to advanced design methods, three similar terms are used in the literature: Generative Design, Generative CAD, and Generative Engineering Design. The main idea lies in the word generative, which captures the nature of algorithms involved in any of these methods. Generative Joinery System and Generative Engineering Design of surface-based components are described using different tools in different applications [5]. They both have in common the outcome, which is not in form of a set of results, and they both deal with assemblies, not only components. What is unique about Generative Joinery System, is the possibility to apply such a method on preparation of a 3D object to be printable using a small-scale printing device.

Although some CAD software developers have already introduced certain tools for engineering designers, which include Generative Design as designation of a module to generate a set of possible designs, this direction is only applicable to a narrow range of products. Nowadays, it is considerably limited to make the software tool general for all existing design problems because of the very wide range of applications and the solutions proposed for them. An advantage of such tool to be accessible for any engineering designer lies in the possibility to develop complex shape products even without significant knowledge of advanced surface modelling. An application of Generative Design module of the Autodesk's Fusion 360 is shown in Fig. 2, where the top three pictures illustrate a simple design of a crane arm. The Generative Design module allows to input boundary conditions, such as exploration envelope, loading limits, positions of fastenings, manufacturing technology, etc. Based on boundary conditions, the final output is generated usually in form of a set of possible geometries, from which 
the designer may choose a suitable solution. Such a procedure is dissimilar to topology optimization, where an initial design is needed to be shape optimized.

Even though the result of such Generative Design procedure is of a complex shape, the patches forming the outer shape are not suitable for surface modelling as they have a bad quality. Therefore, an independent design process is necessary for their modification, which is also limited. It is explained in $[6,8]$ which objectives affect the necessity of high-quality surface connections. In most cases it is required by fabrication technology, aerodynamics behavior and aesthetics.

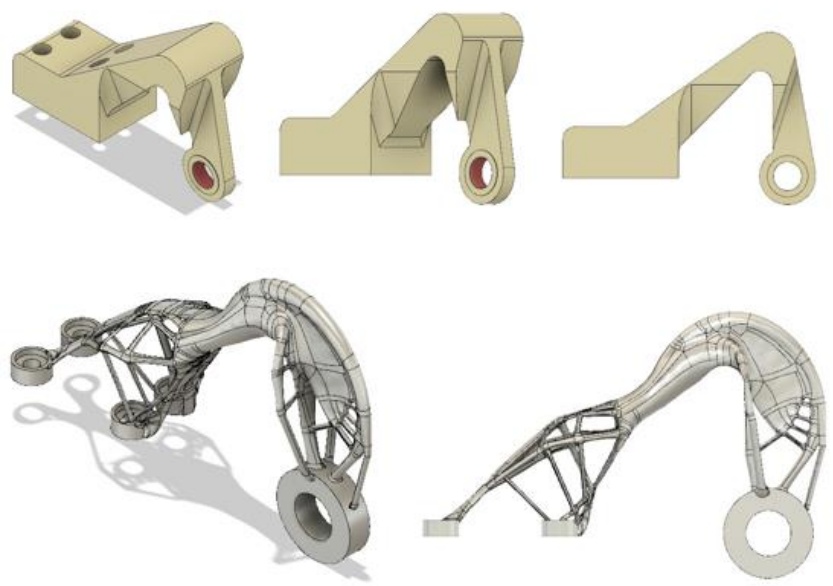

Fig. 2: A crane arm design generated using the Generative Design module of Autodesk's Fusion 360.

Generative Design in the View of Surface Modelling:

The procedure recalled in the following refers to the Generative Engineering Design methodology of shaped components introduced by authors in [4,6,9]. A significant novelty of the presented work lies in the effort of implementing advanced tools for the field of surface-based components designing, where it is significantly restricted. One of the main restrictions is the qualitative definition of surfaces in $\mathrm{CAD}$, rather than quantitative one. Therefore, the standard knowledge-based engineering is not applicable here and programmable design is useful only partially. All this was taken into consideration when a specific Generative Engineering Design methodology was proposed with focus on surfacebased components. Another important task in this context is to support the engineering designers working with complex surfaces to be comparably advanced in engineering work, in contrast with creative artistic designers working with CAS or clay model. Artistic fields are known for implementing a new approach named Generative Design described in [13], however it refers to the generation of a novel artistic work in contrast to products generated in rather technical fields.

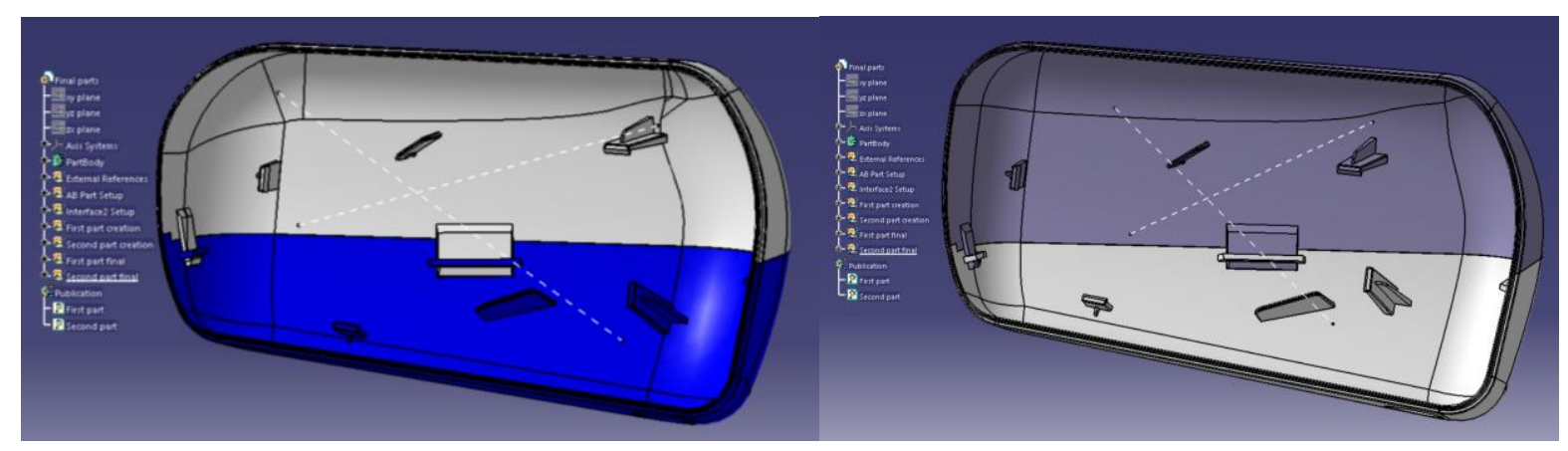

Fig. 3: A simple two-component assembly automatically modified after a different outer shape input. 
The main goal in this field is thus to shift the designing to a higher level by enabling all future components to have a complex shape. It is the most natural way of designing and nature itself has in its nature to save material, minimize resources, and have effective mechanical properties.

Fig. 3 shows automatic generation of connecting elements and inner shape of two components after an outer shape modification.

Design for Additive Manufacturing:

Design for Additive Manufacturing (DfAM) is a new method of modelling and developing components or whole assemblies to fulfill expected functionality and strength while their weight is optimized due to the modern manufacturing technology. In terms of shape complexity of the components, Additive Manufacturing (AM) is less limited than subtractive manufacturing. On the contrary, a disadvantage of $\mathrm{AM}$ is in attainable geometrical tolerances [7]. Generative Design has become an inseparable part of DfAM since an enhancement of product quality is inherently delivered using this tool.

Some of the known characteristics of additive manufacturing: almost no limitations of complex shapes of components, printing of overhangs using supporting structures, lightweight interior structures of various types, almost no tooling, almost no finishing operations (in case of plastic AM technology), and almost no waste.

The goal is thus to interconnect the previously presented modelling approaches with additively manufactured components of high quality, implementing all the advantages the DfAM offers. Strength between the layers and other properties are difficult to estimate since these are quite complex tasks themselves. Therefore, current and future work of the authors is focused on a comprehensive study of mechanical properties of components designed using the Generative Design method and fabricated by the AM technology.

\begin{tabular}{|c|c|c|}
\hline Objective & $\begin{array}{c}\text { Solid modelling } \\
\text { Generative Design as a CAD } \\
\text { module }\end{array}$ & $\begin{array}{c}\text { Surface modelling using } \\
\text { Generative Engineering Design } \\
\text { method }\end{array}$ \\
\hline Boundary conditions & $\begin{array}{l}\text { Quantitative definition } \\
\text { parameters, skeleton, rules, } \\
\text { source code }\end{array}$ & $\begin{array}{l}\text { Qualitative definition } \\
\text { patch continuity, surface of } \\
\text { contact }\end{array}$ \\
\hline Component data & 1 CAD file & At least $\underline{4 \text { CAD files }}$ \\
\hline Design process programming & Boolean operations & $\begin{array}{l}\text { Commands divided into } \\
\text { folders - Geometrical Sets }\end{array}$ \\
\hline Prioritization & $\begin{array}{l}\text { Strict hierarchy based on tree } \\
\text { history sequentially }\end{array}$ & 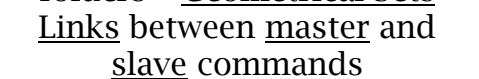 \\
\hline Assemblies & $\underline{\text { No automatic tool }}$ & $\begin{array}{l}\text { Automatic modification } \\
\text { components linked to the } \\
\text { same surface of contact }\end{array}$ \\
\hline Auxiliary modelling entities & Bodies & Wireframes and surfaces \\
\hline Freeform shape of the model & $\begin{array}{l}\text { Result of automatic designing } \\
\text { process - set of results } \\
\text { random patches forming outer } \\
\text { shape }\end{array}$ & $\begin{array}{l}\text { Result of designing process } \\
\text { created once } \\
\text { high quality patches forming } \\
\text { smooth surface }\end{array}$ \\
\hline
\end{tabular}

Tab. 1: Objectives of two different approaches of CAD modelling.

Discussion:

A few complex CAD systems introduced tools for advanced modelling involved in a module known as Generative Design. This module is convenient for applications where specific boundary conditions can be set. When the Generative Design was first introduced in art and architecture, the main idea was to generate a set of outcomes with minimum human intervention. The important task for a designer is to decide whether a procedure of defining limits, boundary conditions and other constraints is effective compared to the design process itself. 
Conclusion:

In this paper we presented another point of view of this advanced design. It is explained why it is advantageous to incorporate surface dimension to automatic methods generating solid objects. Based on the summary in the second section and Fig. 1, it is possible to define the most important objectives implemented in Generative Design tools. These are presented in Tab. 1, which is the main outcome of this study.

Acknowledgement:

The authors gratefully acknowledge the contribution of the Slovak Research and Development Agency under the contracts no. APVV-17-0309 and APVV-17-0006, and the financial support provided by the Cultural and Educational Grant Agency under the contract 041STU-4/2020.

References:

[1] Amadori, K.; Tarkian, M.; lvander, J.; Krus, P.: Flexible and robust CAD models for design automation, Advanced Engineering Informatics, 26(2), 2012, 180-195. https://doi.org/10.1016/j.aei.2012.01.004

[2] Bodein, Y.; Rose, B.; Caillaud, E.: A roadmap for parametric CAD efficiency in the automotive industry, Computer-Aided Design, 45(10), 2013, 1198-1214. https://doi.org/10.1016/j.cad.2013.05.006

[3] Camba, J.D.; Contero, M.: Assessing the impact of geometric design intent annotations on parametric model alteration activities, Computers in Industry, 71(0), 2015, 35-45.

[4] Forrai, M.; Gavačová, J.; Gulan, L.: A practical methodology for creating robust parametric surface-based models in automotive engineering, Procedia CIRP 50, 2016, 484-489. http://doi.org/10.1016/j.procir.2016.04.145

[5] Gulanová, J.; Chen, L.: Applications of Generative Computer-Aided Design, 2020 International CAD Conference, Paris, France, 2018, 199-203. http://dx.doi.org/10.14733/cadconfP.2018.199$\underline{203}$

[6] Gulanová, J.; Gulan, L.; Forrai, M.; Hirz, M.: Generative engineering design methodology used for the development of surface-based components, Computer-Aided Design and Applications, 14(5), 2017, 642-649. http://doi.org/10.1080/16864360.2016.1273581.

[7] Gulanová, J.; Kister, I.; Káčer, N.; Gulan, L.: Evaluation of Various AM Technologies Focused on their Accuracy and Strength, Computer-Aided Design and Applications, 17(6), 2020, 1157-1167. http://doi.org/10.14733/cadaps.2020.1157-1167

[8] Gulanová, J.; Lonek, S.; Gulan, L.: Comparison of two different approaches of a class-A surface creation, 2020 International CAD Conference, Okayama, Japan, 2017, 430-434. https://doi.org/10.14733/cadconfP.2017.430-434

[9] Gulanová, J.; Vereš, M.; Gulan, L.: Surface interpolation and procedure used in the generative engineering design of surface-based automotive components, International Journal of Vehicle Design, 77(4), 2018, 211-226. https://doi.org/10.1504/IJVD.2018.099710

[10] Hsiao, S.W.; Chuang, J.C.: A reverse engineering-based approach for product form design, Design Studies, 24(2), 2003, 155-171. https://doi.org/10.1016/S0142-694X(02)00030-3

[11] Krish, S.: A practical generative design method, Computer-Aided Design, 43(1), 2011, 88-100. https://doi.org/10.1016/j.cad.2010.09.009

[12] Ledermann, C.; Hanske, C.; Wenzel, J.; Ermanni, P.; Kelm, R.: Associative parametric CAE methods in the aircraft pre-design, Aerospace Science and Technology, 9(7), 2005, 641-651. https://doi.org/10.1016/j.ast.2005.05.001

[13] Processing, https://processing.org/, Ben Fry and Casey Reas.

[14] Schut, E.J.; Van Tooren, M.J.L.: A knowledge-based engineering approach to automation of conceptual design option selection, 45th AIAA Aerospace Sciences Meeting and Exhibit, AIAA Paper, 968, 2007.

[15] Verhagen, W.J. et al.: A critical review of knowledge-based engineering: an identification of research challenges, Advanced Engineering Informatics, 26(1), 2012, 5-15. 